\title{
Questionários gamificados para a disciplina de História e sua utilização no Ensino Médio Integrado
}

\section{Gamified questionnaires for the History subject and its use in Integrated High School}

\author{
PRISCILA CABREIRA DE FREITAS \\ Instituto Federal de Educação, Ciência e Tecnologia de São Paulo - Câmpus Sertãozinho \\ DANILO FISCHER \\ Instituto Federal de Educação, Ciência e Tecnologia de São Paulo - Câmpus Sertãozinho \\ NEMÉSIO FREITAS DUARTE FILHO \\ Instituto Federal de Educação, Ciência e Tecnologia de São Paulo - Câmpus Sertãozinho
}

\begin{abstract}
Resumo: Considerando o trabalho como uma forma de produzir a história, compreende-se a importância do conhecimento histórico na conscientização do papel dos cidadãos na sociedade. $\mathrm{Na}$ busca de alternativas para despertar maior interesse dos alunos nas aulas de História e sabendo do potencial motivador das tecnologias em sala de aula, foi elaborado um produto educacional na forma de quizzes sobre as relações de trabalho na História do Brasil, gamificados na plataforma Kahoot!. O estudo de caso demonstrou que para a maioria dos alunos participantes (via questionário online), a aplicação dos quizzes nas aulas favoreceu o ensino-aprendizagem, a reflexão sobre os acontecimentos históricos sobre "relações de trabalho" e a associação destes fatos as suas realidades, gerando maior interesse e motivação por parte dos alunos.
\end{abstract}

Palavras-chave: Ensino Médio Integrado. Ensino de História. Aprendizagem móvel. Kahoot!

\begin{abstract}
Considering work as a way of producing history, it is possible to understand the importance of historical knowledge in raising awareness of the role of citizens in society. In the search for alternatives to increase the interest of students in History classes and knowing the motivating potential of technologies in the classroom, an educational product was developed in the form of quizzes about work relationships in the History of Brazil, gamified on the Kahoot! platform. The case study demonstrated that for most of the participating students (via online questionnaire) the application of quizzes in class favored teaching-learning, reflection on historical events about "work relationships" and the association of these facts with their realities, generating greater interest and motivation on the part of the students.
\end{abstract}

Keywords: Integrated High School. Teaching History. Mobile learning. Kahoot!

FREITAS, Priscila Cabreira de; FISCHER, Danilo; DUARTE FILHO, Nemésio Freitas. Questionários gamificados para a disciplina de História e sua utilização no Ensino Médio Integrado. Informática na Educação: teoria \& prática, Porto Alegre, v. 23, n. 2, p. 104-122, maio./ago. 2020. 


\section{Introdução}

Em toda a sua trajetória, a Educação no Brasil foi diretamente influenciada pela divisão social em classes, o que resultou na chamada dualidade educacional: a educação formal proporcionava às elites o acesso aos conhecimentos científico-tecnológicos e histórico-sociais (CIAVATTA, 2005) e a educação profissional (por muito tempo, informal) era destinada à classe trabalhadora, promovendo a qualificação de mão de obra para atividades exclusivamente operacionais e, posteriormente, fabris (MOURA, 2007). Na busca pela superação dessa dicotomia, a proposta de Ensino Médio Integrado a cursos técnicos (EMI) não é somente preparar os alunos para o mercado de trabalho, mas também torná-los cidadãos críticos e reflexivos. Trata-se do conceito de formação integral, que abarca os conhecimentos específicos e gerais, incluindo os históricos, para o desenvolvimento omnilateral do indivíduo.

Ramos (2014) concebe que os humanos são seres histórico-sociais, pois a partir de suas atuações no mundo produzem conhecimento, com o intuito de satisfazer necessidades sociais e subjetivas. Neste sentido, entende-se que é por meio do trabalho que vão sendo produzidas e apropriadas a história da humanidade e a história do conhecimento. E assim, destaca-se a importância de democratizar o acesso ao conhecimento histórico, uma vez que todos produzem história por meio do trabalho e precisam ter consciência de seus papéis na sociedade.

No entanto, quando se fala em ensino de História, é inevitável observar a associação às aulas pouco interativas, em que muitas vezes se prioriza a memorização de fatos e datas. Assim, o aluno não se percebe inserido no que está sendo apresentado, não consegue relacionar o conhecimento ao seu cotidiano e nem refletir de que forma aquilo pode ter influência sobre a sua vida. Estes obstáculos dificultam que se atinja o objetivo da disciplina, que é a apropriação dos fatos passados, visando a associação ao presente e a projeção consciente do futuro, estimulando a autonomia intelectual e o pensamento crítico (SEVERO SOBRINHO, 2014).

Diante dessa necessidade de renovar as práticas de ensino, destacam-se as tecnologias, tão presentes no cotidiano de todos, que vêm sendo cada vez mais utilizadas de forma estratégica no processo de ensino-aprendizagem. Dentre elas destaca-se a aprendizagem móvel (mobile learning ou m-learning), que envolve a utilização de tecnologias móveis, com o objetivo de possibilitar a aprendizagem a qualquer hora e em qualquer lugar, por meio de aparelhos eletrônicos e digitais móveis em sala de aula, como os smartphones, por exemplo (UNESCO, 2014).

Outra área que vem crescendo no meio educacional é a de jogos educativos, em especial a aprendizagem baseada em jogos (Game-Based Learning), que utiliza jogos completos (e não somente elementos de jogos) em seu formato, sendo seu objetivo principal o ensino (ESQUIVEL, 2017). Existem plataformas que oferecem várias possibilidades de criação de games, como por exemplo, os quizzes, que são jogos baseados em questionários previamente inseridos. 
Neste contexto, dadas as dificuldades no ensino-aprendizagem de História e o potencial motivador das tecnologias na educação, o objetivo desta pesquisa foi criar um conjunto de questionários (quizzes) que abordasse as relações de trabalho nos períodos históricos do Brasil, disponibilizando-os na plataforma Kahoot!. Para a orientação do professor aplicador, foi gerado um manual. Os quizzes, que são respondidos pelos alunos a partir de dispositivos e redes móveis, buscam incentivar a aprendizagem por meio da motivação e engajamento proporcionados pelo jogo. O intuito é, também, observar de que forma o produto educacional pode colaborar para o ensino-aprendizagem na disciplina de História no EMI.

\section{Ensino Médio Integrado e Ensino de História}

A formação profissional teve princípio no século XIX, e suas primeiras experiências tinham como objetivo amparar pobres e órfãos desfavorecidos social e financeiramente, prevenindo ações e condutas consideradas desviadas dos bons costumes (CAMPELLO, 2009; RAMOS, 2014). Neste cenário, já é possível notar a segregação social refletida na educação, gerando uma dualidade educacional.

Na década de 1930, a industrialização e a modernização das relações produtivas tornaram indispensável uma estruturação da educação, o que levou o governo, em consonância com a classe capitalista, a repensar a qualificação dos trabalhadores. Afinal, para lidar com os novos aparatos tecnológicos e maquinários era necessário não somente a execução de trabalho manual, mas também certa formação intelectual. A partir deste momento, a educação passa a ter regulamentação por meio de decretos e leis orgânicas. (MOURA, 2007; VIEIRA; SOUZA JUNIOR, 2016).

Durante as últimas décadas, as discussões relacionadas às demandas educacionais promoveram alterações na legislação do ensino profissional, com a proposta de superar a dicotomia entre educação geral e específica. Mas isso acabava não acontecendo, seja pela manutenção de currículos desiguais ou pelas dificuldades em se colocar a legislação em prática. Consequentemente, a proposta de educação pública, gratuita, laica e de qualidade a todos foi perdendo força, conservando-se a lógica de mercado (MOURA, 2007; TAVARES, 2012; VIEIRA; SOUZA JUNIOR, 2016).

Em 2003, diante da mudança de governo, as discussões no campo da educação profissional foram retomadas, trazendo novamente o debate sobre a educação politécnica, unitária e universal e a necessidade de se superar a dualidade entre cultura geral e técnica. Com isso, entre as propostas, foi elaborada uma solução transitória, porém viável, com intuito de promover um tipo de ensino médio que garantisse a integralidade das dimensões da formação básica e da profissional (MOURA, 2007).

Essa proposta ideológica leva em conta as constantes mudanças no mundo do trabalho e promove uma percepção atualizada quanto à relação entre ciências e trabalho, substituindo o simples "fazer" por ações que envolvam conhecimento científico, criatividade, criticidade e capacidades cognitivas (RAMOS, 2014). Kuenzer e Lima (2013) salientam a importância de se 
desenvolver nos sujeitos a capacidade de associar teoria e prática, visando também a interação com as inovações tecnológicas. Sendo assim, torna-se essencial a integração de todas as dimensões da vida dos sujeitos no processo educativo para que se alcance a formação omnilateral e, para atingir esse objetivo, ressalta-se a importância do conhecimento histórico.

Para Ramos (2014, p. 107), "na perspectiva da relação entre parte-totalidade numa visão histórica, o conhecimento contemporâneo guarda em si a história da sua construção". Isso porque a humanidade vem buscando compreender e transformar fenômenos sociais e naturais por meio dos conhecimentos ao longo da história. E a produção científica garante a transmissão dos conceitos por gerações, além de permitir questionamentos e superá-los pela construção de novos conhecimentos. Fica comprovada, então, a interdependência entre a apropriação do conhecimento histórico e os avanços que se espera em todos os aspectos da sociedade.

Ainda assim, muitos alunos não compreendem o papel desta disciplina na grade curricular e na sua vida. Caimi, em 2006, já questionava o porquê de os alunos não conseguirem significar a aprendizagem de História em suas vidas e não apreenderem os conhecimentos satisfatoriamente na educação básica. Fato é que aulas com conteúdos densos e extensos tornam-se maçantes e desinteressantes, dificultando a aprendizagem. Neste sentido, Silva Júnior, Silva e Santos (2013) sugerem que o uso de fontes e linguagens diversificadas pode colaborar para que o ensino de História cumpra sua função na formação do indivíduo, ressaltando que a compreensão da História não pode ser tida como algo acabado, mas aberta a interpretações. E como consideram Silva e Figueiredo (2013), não é mais possível resistir às mudanças trazidas pela tecnologia, sendo os recursos tecnológicos utilizados na dinamização das aulas, desenvolvimento da consciência crítica e motivação para a participação dos alunos nas aulas de História.

Contudo, não se pode esperar que a aplicação destas inovações garanta uma maior eficiência no ensino-aprendizagem por si só: o docente também deve aprimorar seu modo de pensar o ensino. Portanto, a introdução de novas propostas tecnológicas demonstra-se relevante para a educação integral e o ensino de História, se adaptadas, articuladas e contextualizadas.

\section{Aprendizagem Móvel}

A constante evolução tecnológica tem causado grandes mudanças na sociedade, inclusive nas relações de poder e de trabalho (MIZUKAMI et al., 2002 apud OLIVEIRA et al., 2018). Isso demanda da área educacional uma adequação para essa nova realidade, com intuito de promover aos alunos interações com as inovaçãos tecnológicas, que atualmente também são essenciais no mundo do trabalho. Para Ramos (2014), os conceitos tecnologia, trabalho, ciência e cultura são indissociáveis e integrados à formação politécnica, sendo possível o desenvolvimento das potencialidades dos indivíduos e o atendimento ao princípio da formação integral. 
As TIC (Tecnologias de Informação e Comunicação), por exemplo, têm sido utilizadas para aprimorar a qualidade do ensino, colaborar para a inclusão social e o desenvolvimento socioeducativo e trazer mais interatividade e inovação (CHIOFI e OLIVEIRA, 2014). O uso de aparelhos móveis e tecnologias ubíquas têm sido destaque por disponibilizar informação instantaneamente, sendo a aprendizagem móvel uma TIC que utiliza tais tecnologias.

Como cita a UNESCO (2014), a aprendizagem móvel busca propiciar a acessibilidade a informações e conhecimentos, utilizando aparelhos eletrônicos, digitais, portáteis, com acesso à internet e aspectos multimídias, em qualquer lugar e hora, favorecendo, conforme Sagarmay Deb (2012, apud Lima, 2016) uma participação mais ativa e colaborativa. Além disso, de acordo com Belém (2014, apud Pereira, Pereira e Alves, 2015), tal participação é fundamental no engajamento dos alunos quanto à utilização de plataformas de aprendizagem móvel, sendo as interações mais valiosas do que a própria tecnologia, por propiciar condições motivacionais na aprendizagem.

Arancillo et al. (2012, apud Lima, 2016) ressaltam que a aprendizagem móvel pode ser usada como ferramenta auxiliar da aprendizagem, contanto que a maioria dos estudantes portem um aparelho móvel a maior parte do tempo. Para isso, considera-se o fato de que os aparelhos móveis e a internet têm se tornado cada vez mais acessíveis às diferentes classes sociais, contribuindo para a redução da desigualdade de oportunidades e colaborando para a superação da dualidade educacional.

Moraes (2017, p. 63), diz que

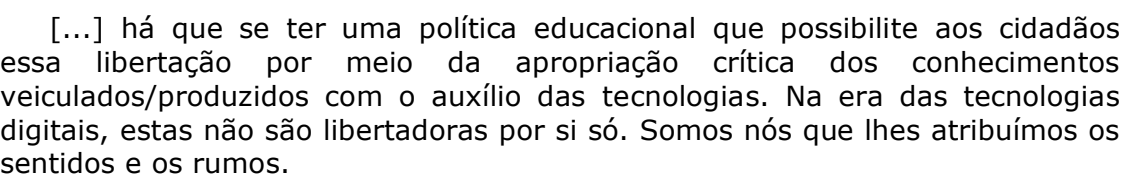

Assim, a inclusão digital deve promover a apropriação consciente da tecnologia, para que o aluno seja capaz de decidir como, quando e para que irá utilizá-la (DE LUCA, 2004; PELLANDA, 2005 apud AMORIM et al., 2016). Neste contexto, a aprendizagem móvel é destacada por propiciar o acesso à informação de forma mais interativa e estimulante, e dentre as opções para seu uso encontram-se os jogos digitais.

\section{Aprendizagem Baseada em Jogos Digitais}

No contexto tecnológico, Prensky (2012) define "jogos" como formas de diversão e brincadeiras compostas por elementos estruturais básicos: regras, metas ou objetivos, resultados e feedback, conflito/competição/desafio/oposição, interação (social) e representação e enredo. No que diz respeito aos "jogos digitais", o autor acrescenta outros elementos e vantagens: design; adaptabilidade; recompensa (vitória); interatividade com o jogo e resolução de problemas; automatização de detalhes e regras; são mais rápidos e possuem mais reações; são mais divertidos (experiências incomuns ou impossíveis); melhores representações gráficas; 
podem ser jogados contra a inteligência artificial; atualização instantânea e número irrestrito de conteúdos e cenários.

O processo de gamificação surgiu a partir dos elementos básicos. Gamificação, de acordo com Deterding et al. (2011, apud Esquivel, 2017, p. 14), é "o uso de elementos presentes nos jogos em contextos externos aos mesmos". Para Vianna et al. (2013, apud Figueiredo, Paz e Junqueira, 2015) "refere-se ao uso de mecanismos e dinâmicas de jogos para a resolução de problemas e para a motivação e o engajamento de um determinado público em uma atividade ou tarefa".

Esquivel (2017) destaca que, após o surgimento da gamificação, outros termos referentes ao uso de jogos para aprendizagem foram aparecendo. Um deles é o Game-Based Learning, (Aprendizagem Baseada em Jogos), apresentado por Leitão (2013, p. 27) como:

[...] um processo de envolvimento rápido no qual os jogos de computador educacionais são integrados numa abordagem educacional tradicional. Este tipo de jogos motiva e ajuda os estudantes a adquirirem novos conhecimentos e habilidades de uma forma em que no ensino tradicional não seria viável ou poderia ser difícil de alcançar. Nestes jogos, educação e entretenimento coexistem e ajudam a alcançar melhores resultados de aprendizagem.

Com a utilização de jogos digitais e virtuais no contexto da Aprendizagem Baseada em Jogos, surgiu o termo Digital Game-Based Learning, (Aprendizagem Baseada em Jogos Digitais). Prensky (2012 apud Oliveira et al., 2018, p.147) o define como "um processo interativo de alto envolvimento, que permite um diálogo mais equitativo entre teoria e prática [...] a união entre um conteúdo educacional e os jogos de computador".

A Aprendizagem Baseada em Jogos Digitais pode contribuir para a assimilação de conteúdos que as pessoas geralmente não se sentem motivadas a aprender (OLIVEIRA et al., 2018) e é eficaz por usar técnicas de aprendizagem interativa (não originadas de jogos) integradas às que são utilizadas em jogos comerciais (SENA et al., 2016).

Entende-se que por meio de jogos educacionais é possível, então, desenvolver a aprendizagem dos indivíduos, uma vez que envolve aspectos psicológicos, comportamentais, sociais, educacionais e cognitivos. Há também o fomento da formação integral, pois abrange elementos da vivência do aluno, considera seu cotidiano e integra novos conhecimentos de maneira interessante e transformadora.

No contexto da História, Sousa e Pereira (2015, p. 2) identificam que a oferta de jogos dessa temática cresce a cada dia, "[...] trazendo, reconstruindo e aproximando mundos distantes de nossa realidade, fazendo-nos imergir em ambientes históricos muitas vezes quase que perfeitos $[\ldots]^{\prime \prime}$. Atualmente, existe uma diversidade de propostas de aplicação da aprendizagem baseada em jogos digitais, tendo sido escolhida para esta pesquisa uma plataforma para gamificação de conteúdo chamada Kahoot!.

\section{Metodologia}

Esta pesquisa foi classificada como de natureza aplicada, uma vez que buscou produzir conhecimentos para aplicação prática, e com objetivo explicativo, pois aprofundou o 
conhecimento da realidade, explicando as causas e motivações de acontecimentos, por meio de análise, classificação e interpretação dos registros e fenômenos (GIL, 2010; PRODANOV; FREITAS, 2013).

O estudo de caso foi o procedimento selecionado por ser o mais apropriado para a verificação de um "fenômeno contemporâneo dentro de seu contexto real" (YIN, 2005 apud GIL, 2010, p. 54), e considerando-se "o caráter do estudo de caso, independente de sua linha metodológica, fica claro que ele apresenta alto valor para o estudo das inovações educacionais" (LEONARDOS; GOMES; WALKER, 1994, p. 12).

Os procedimentos técnicos escolhidos foram a revisão bibliográfica, que permite acessar amplamente os fenômenos que estão em foco no estudo, trazendo embasamento teórico (GIL, 2010; PRODANOV; FREITAS, 2013) e o questionário, que é um conjunto de questões articuladas de forma sistemática, com o objetivo de conhecer as opiniões dos indivíduos pesquisados sobre o assunto abordado no estudo (SEVERINO, 2007).

Trata-se de pesquisa quanti-qualitativa, dada a impossibilidade de eleger entre a abordagem quantitativa (tratamento dos dados numéricos de forma estatística) e qualitativa (interpretação e significação das informações por meio da análise desse conteúdo). Esta combinação permite uma visão de maior confiabilidade e ampla dos resultados (LAVILLE; DIONNE, 1999; SOUZA; KERBAUY, 2017).

Os procedimentos metodológicos foram esquematizados em cinco etapas:

- Primeira etapa - Estruturação teórica do trabalho: escolha do tema, levantamento bibliográfico preliminar, formulação de problema de pesquisa, organização da fundamentação teórica e elaboração de questionário para coleta de dados.

- Segunda etapa - Criação do produto educacional: estudo do tema para produção de questionários temáticos, criação de questionários para gamificação sobre relações de trabalho, análise e validação por profissional da área, transcrição dos questionários para a plataforma Kahoot!, elaboração da identidade visual do produto educacional e realização de testes.

- Terceira etapa - Aplicação do produto educacional e coleta de dados.

- Quarta etapa - Tratamento e análise de dados.

- Quinta etapa - Apresentação das considerações finais e elaboração de Manual do Professor.

\section{Produto Educacional}

A ferramenta selecionada para o desenvolvimento do produto educacional foi a plataforma Kahoot!, que disponibiliza versão gratuita para professores e alunos, na qual o objetivo é criar quizzes a partir da inserção de questões. Desta forma, o "responder questões" envolve vários elementos de jogos, como interatividade, pontuação, tempo, ranking, trilha sonora e design que remetem aos jogos comerciais, que são muito apreciados e acessados pelos jovens. É possível, também, incluir imagens e vídeos e escolher entre vários tipos de gamificação, dentre 
elas o jogo individual ou em grupo, questões com uma ou mais respostas corretas e até perguntas abertas.

A plataforma pode ser acessada em computadores (por meio do site) e dispositivos móveis (por meio do site ou aplicativo). Apesar de disponibilizada em inglês, é possível utilizar a "tradução da página" nos navegadores de internet, o que facilita o acesso e a compreensão das informações.

Para o recurso didático proposto, o formato de jogo selecionado foi:

- Participação individual (um jogador por dispositivo móvel);

- Questões com quatro alternativas, sendo uma correta;

- Utilização de ranking;

- Tempo de 30 segundos por questão para responder;

- Inclusão de imagens;

- Uso de computador, caixas de som e projetor pelo docente e dispositivos móveis pelos discentes;

- Acesso pelo site da plataforma.

As questões gamificadas são limitadas a 95 caracteres nas perguntas e 60 em cada alternativa (incluindo espaços), garantindo melhor jogabilidade, dado o tempo cronometrado. Ao final de cada questão, são disponibilizados a pontuação e o ranking parcial dos cinco primeiros colocados e, após a última questão, é apresentado um podium final, considerando as três melhores pontuações totais. Vale enfatizar que a utilização de ranking é opcional.

O produto educacional consiste em um conjunto de questionários, divididos em dois níveis de dificuldade, que foram gamificados na plataforma Kahoot!, a ser aplicado em sala de aula com o uso de dispositivos móveis conectados à internet. O tema selecionado foi a História do Brasil, destacando as relações de trabalho e assuntos afins.

A História do Brasil foi dividida em Períodos, totalizando onze aulas e vinte e dois quizzes (um pré e um pós-aula para cada):

- Pré-Colonial;

- Colonial;

- Imperial (Primeiro Reinado, Regências, Segundo Reinado); e

- Republicano (República da Espada, República Oligárquica, Era Vargas, República Populista, Ditadura Militar, Nova República). 
Figura 1: Captura de tela: à esquerda, visão do computador que será projetada na parede; à direita, visão no dispositivo móvel utilizado pelos alunos
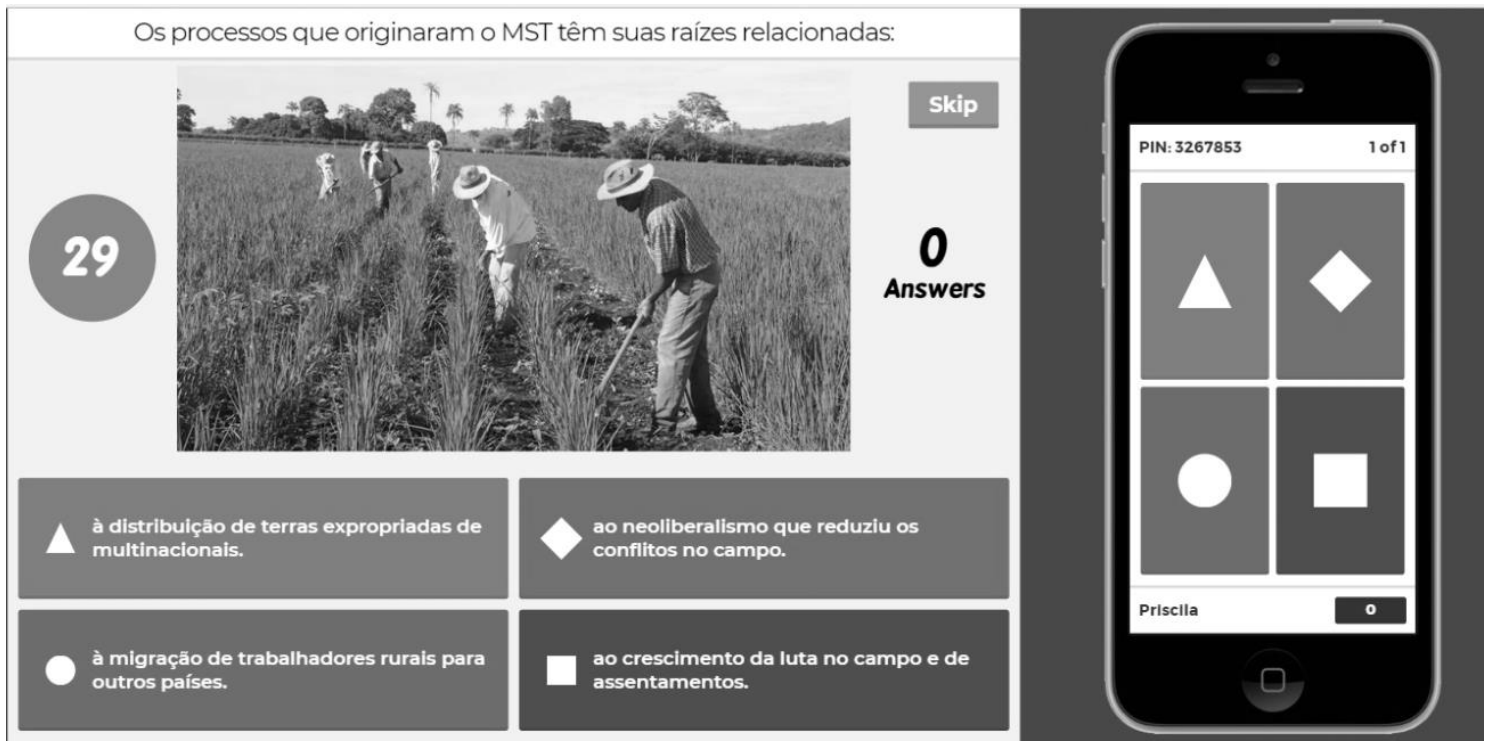

Fonte: Questão gamificada pela autora - Kahoot!

Figura 2: Captura de tela: à esquerda, o resultado geral projetado do computador para a parede; à direita, visão no dispositivo móvel, após resposta correta

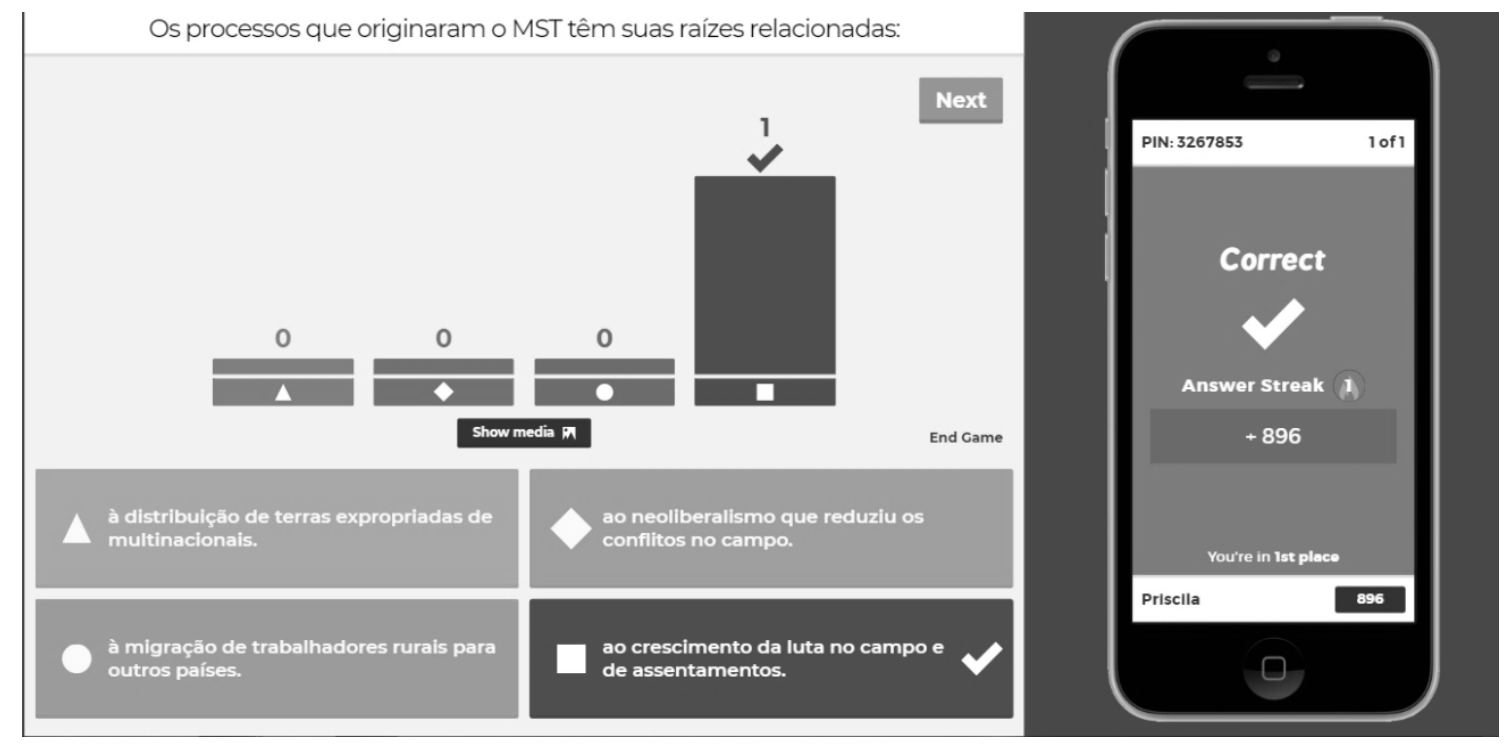

Fonte: Questão gamificada pela autora - Kahoot!

A elaboração e ministração dos conteúdos ficam a encargo do professor, considerando as necessidades de cada turma, as possibilidades habituais e os tópicos citados nos quizzes (vide Manual do Professor ${ }^{1}$ ), de forma a correlacionar os fatos históricos com os eventos atuais e favorecer o maior envolvimento entre professor/alunos/conteúdo durante a aula.

\footnotetext{
${ }^{1}$ Acessível em: https://educapes.capes.gov.br/handle/capes/552628.
} 
O manual digital, que foi disponibilizado no repositório da EduCapes, garantindo o acesso a qualquer público, contém as orientações para a criação de conta na plataforma Kahoot! e a utilização dos quizzes, as questões pré e pós-aulas para cada período histórico, a alternativa correta de cada pergunta e um comentário que justifica tal resposta.

Os quizzes pré-aulas contêm três questões mais fáceis e têm como objetivos despertar interesse pelo assunto e verificar os conhecimentos prévios, para possíveis adaptações do conteúdo às necessidades de cada turma. Já os quizzes pós-aulas possuem cinco questões mais difíceis, utilizadas para revisão da aula, com a intenção de incentivar o aluno à reflexão sobre os acontecimentos e a conexão ao seu contexto social atual.

\section{Estudo de Caso, Resultados e Discussão}

A aplicação da pesquisa ocorreu no Instituto Federal de São Paulo - Câmpus São João da Boa Vista em 2018 e 2019. Considerando as aulas disponibilizadas para a pesquisa, os períodos abordados foram o "Pré-Colonial" e o "Colonial" para as turmas de 2018 e o "Período Imperial" (Primeiro Reinado e Regências) para as de 2019, com ministrações da própria pesquisadora.

Após breve explicação sobre a pesquisa, iniciou-se a primeira etapa da aula, que consistiu na interação com o quiz pré-aula. Logo após, ocorreu uma breve explicação para cada questão, facilitando a compreensão da resposta correta. Na sequência, houve a ministração da aula temática, e ao seu término os alunos conectarem-se novamente à plataforma Kahoot! e responderam as cinco questões pós-aula. A justificativa para a resposta certa ocorreu em seguida.

As duas aulas foram sequenciais, tendo sido disponibilizado o questionário de pesquisa para ser respondido virtualmente ao final da segunda. O questionário continha doze questões dos tipos abertas, semiabertas e fechadas, estando dividido em três seções (caracterização do público, percepções quanto à disciplina de História e identificação das opiniões quanto ao uso de dispositivos móveis em sala de aula e ao produto educacional aplicado).

A primeira seção caracterizou o grupo como alunos do $4^{\circ}$ ano do Ensino Médio Integrado ao Técnico em Informática, divididos em quatro turmas, totalizando 88 respondentes do questionário de pesquisa. Vale salientar que o referido produto educacional pode ser utilizado em quaisquer cursos de EMI e em outros contextos.

Na segunda seção, buscou-se verificar as percepções desses alunos em relação à disciplina de História. Sobre a importância que acreditavam ter a disciplina de História em suas formações, 67 (76,14\%) concordaram totalmente; 15 (17,05\%) concordaram parcialmente e 6 $(6,81 \%)$ não concordaram, nem discordaram. As opções "Discordo parcialmente" e "Discordo totalmente" não foram apontadas (Gráfico 1 ). 


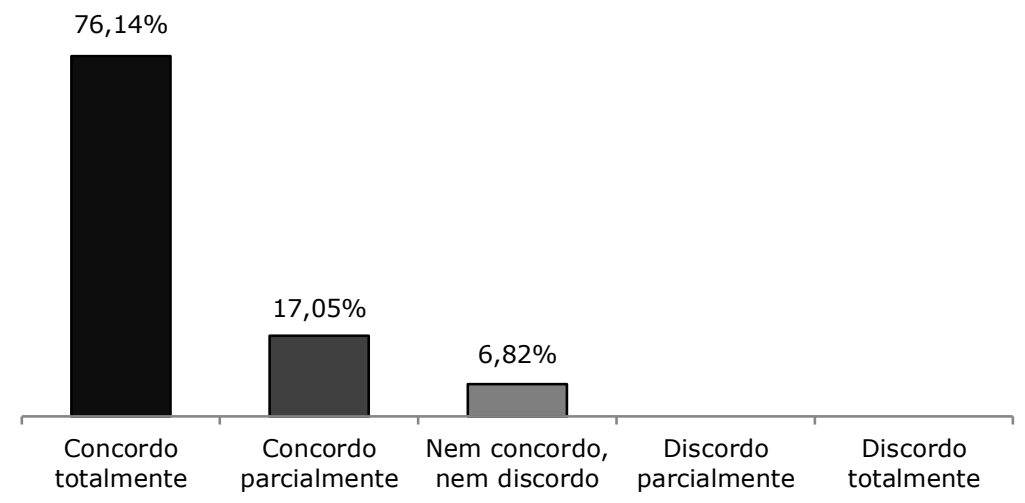

Fonte: autora.

Assim, foi possível constatar que a maioria dos alunos compreende a importância do conhecimento de fatos e acontecimentos históricos para a sua formação.

$\mathrm{Na}$ questão que tratava do interesse pelas aulas e conteúdo da disciplina, $28(31,8 \%)$ optaram por "Concordo totalmente", 38 (43,2\%) por "Concordo parcialmente", 16 (18,2\%) por "Nem concordo, nem discordo", 2 (2,3\%) por "Discordo parcialmente" e 4 (4,5\%) por "Discordo totalmente (Gráfico 2).

Gráfico 2: "As aulas e os conteúdos sobre História costumam despertar o seu interesse?"

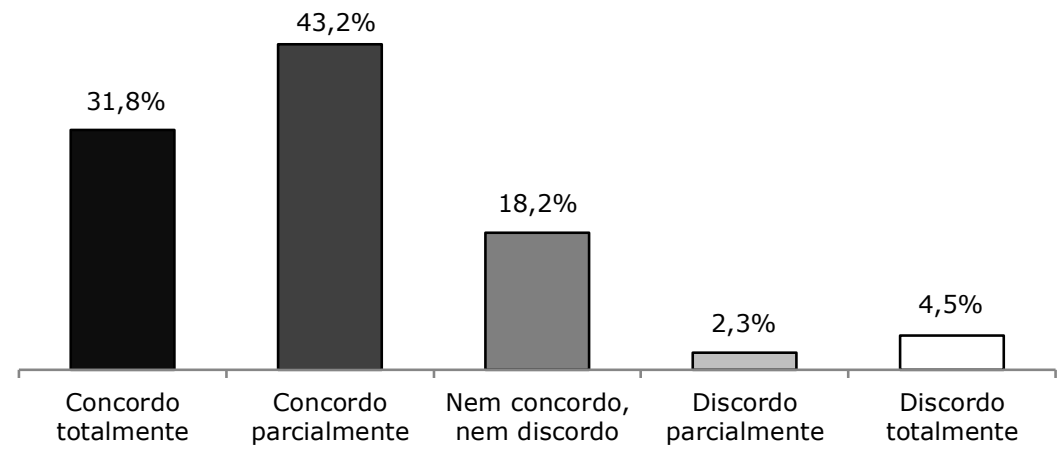

Fonte: autora.

Grande parte dos participantes demonstrou ter interesse pelos conhecimentos históricos, mas aproximadamente um quarto deles não se sente estimulado ao aprendizado de História.

Questionados sobre a frequência de utilização de recursos e/ou tecnologias digitais nas aulas de História, 2 (2,3\%) responderam "Muito", 27 (30,7\%) optaram por "Às vezes", 35 $(39,8 \%)$ entenderam que "Pouco", 18 (20,5\%) selecionaram "Nunca" e 6 (6,8\%) justificaram com "Não sei responder" (Gráfico 3). 


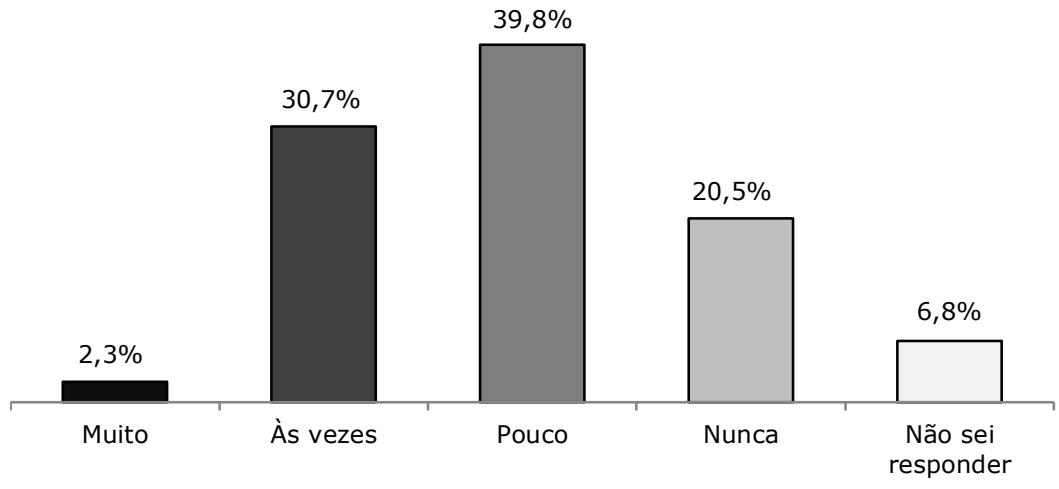

Fonte: autora.

Com maioria de respostas em "às vezes" e "pouco", conclui-se que o uso de recursos tecnológicos ainda não é utilizado com frequência nas aulas de História, elementos estes que poderiam promover experiências mais motivadoras e que colaborassem para a participação dos alunos.

Àqueles que escolheram as três primeiras alternativas da questão 3, ainda foi perguntado quais eram os recursos e/ou tecnologias digitais empregados nas aulas. Das 68 citações, a maioria referiu-se ao uso de celulares e do aplicativo Whatsapp (disponibilização de materiais e tarefas), apresentações de slides e projeções e também a utilização de computadores e internet. Menos citados, constam a exibição de vídeos e envio de arquivos digitais. Nesta análise, verificou-se que os dispositivos móveis e internet até são usados durante a aula, mas unicamente para a disponibilização de materiais, o que restringe a interatividade de alunos, professor e conteúdo entre si. Por sua vez, os computadores e equipamentos de projeção fazem parte da infraestrutura das salas de aula e laboratórios, sendo aparatos já comuns a alunos e docentes do Câmpus.

A terceira seção buscou a opinião quanto ao uso de dispositivos móveis em sala de aula e sobre o produto educacional. Sua primeira questão solicitou a opinião dos participantes quanto à colaboração que recursos e tecnologias digitais poderia ter para tornar as aulas História mais dinâmicas e participativas, tendo $71(80,7 \%)$ dos participantes concordado totalmente, 12 $(13,6 \%)$ concordado parcialmente, $3(3,4 \%)$ não concordado e nem discordado, $1(1,1 \%)$ discordado parcialmente e $1(1,1 \%)$ discordado totalmente (Gráfico 4). 
Gráfico 4: "Você acredita que o uso de recursos e tecnologias digitais para o ensino de História pode tornar as aulas mais dinâmicas e participativas?"

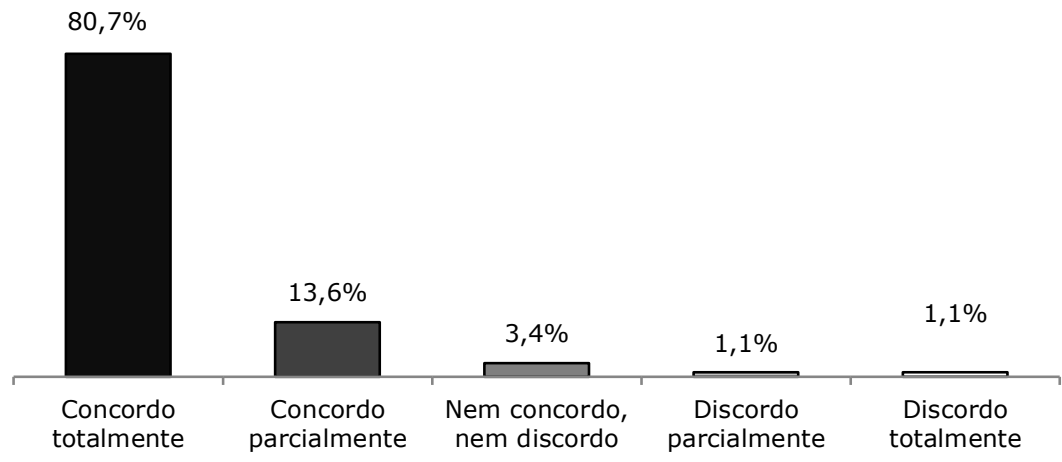

Fonte: autora.

Esse resultado comprovou que o uso de recursos tecnológicos é bem aceito pelos discentes, pois compreendem que tais aplicações podem tornar as aulas mais dinâmicas e participativas.

Aos alunos também foi perguntado sobre a colaboração dos quizzes no sentido de melhorar a compreensão quanto às relações de trabalho nos períodos históricos apresentados. Assim, $52(59,1 \%)$ selecionaram "Concordo totalmente", 24 (27,3\%) "Concordo parcialmente", 11 $(12,5 \%)$ "Nem concordo, nem discordo", 1 (1,1\%) "Discordo parcialmente e nenhum "Discordo totalmente" (Gráfico 5).

Gráfico 5: "Em sua opinião, a utilização dos quizzes na plataforma Kahoot! colaborou para uma melhor compreensão quanto às relações de trabalho em cada período histórico do Brasil?"

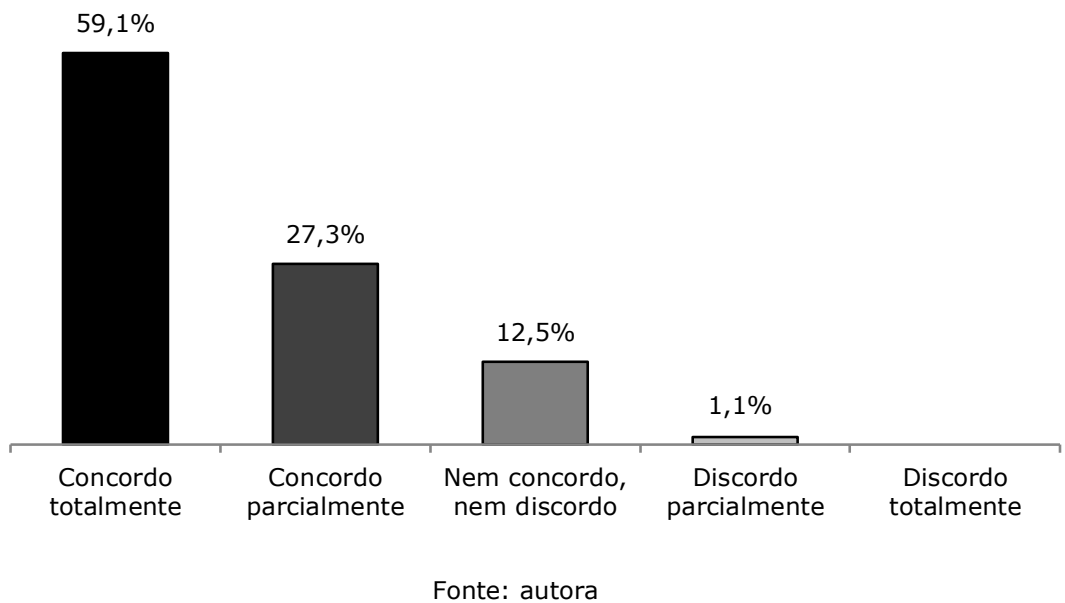

Observou-se que a maioria $(86,4 \%)$ dos alunos sugeriu que a aplicação do recurso didático durante as aulas cooperou para a compreensão sobre as relações de trabalho nos períodos históricos estudados, sendo este o foco temático do produto educacional.

Quando perguntados sobre o poder do recurso didático em despertar mais interesses e motivação a participarem das aulas, 55 (62,5\%) concordaram totalmente, 22 (25\%) 
concordaram parcialmente, 7 (8\%) não concordaram nem discordaram, $1(1,1 \%)$ discordou parcialmente e $3(3,4 \%)$ discordaram totalmente (Gráfico 6).

Gráfico 6: "Você se sentiu mais interessado e motivado a participar das aulas em que o recurso didático proposto foi utilizado?"

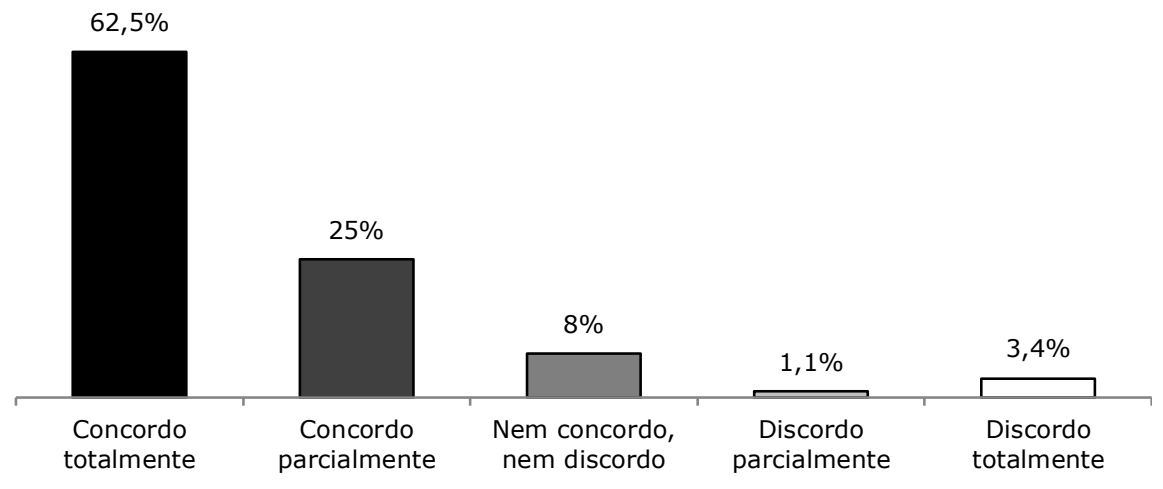

Fonte: autora.

O resultado comprova que para $87,5 \%$ dos alunos, o produto educacional aumentou o interesse e a motivação para participar das aulas propostas, quando comparadas às aulas tradicionais.

Na próxima pergunta, foi indagado se, na opinião deles, o uso de dispositivos móveis de forma consciente e direcionada em sala de aula poderia colaborar ou atrapalhar no ensinoaprendizagem. Para 84 alunos $(95,5 \%)$ a resposta foi "Colaborar", para 1 (1,1\%) foi "Atrapalhar" e que escolheram "Não sei responder" foram 3 (3,4\%). O resultado comprova que a maior parte dos pesquisados vê de forma positiva a utilização de dispositivos móveis durante as aulas (de forma consciente e direcionada), podendo colaborar para o trabalho do professor e o aprendizado do aluno. Para isso, é importante que a atenção dos alunos esteja voltada à aula, sem distração com os aparelhos, e neste caso, os quizzes são favoráveis, por exigirem uma interação com concentração e velocidade.

Em seguida, solicitou-se a opinião dos pesquisados quanto ao recurso didático e ao uso de dispositivos móveis nas aulas, indicando pontos positivos e negativos, resultando 147 apontamentos positivos, 23 negativos e 1 indiferente. O uso do produto educacional e de dispositivos móveis durante a aula foi considerado bastante interessante. Os apontamentos positivos quanto ao produto educacional e aos dispositivos móveis foram sintetizados em: tornaram a aula mais interessante, divertida, atrativa, dinâmica e motivaram a participação; aceleraram e facilitaram o aprendizado e a associação dos conteúdos; estimularam a concentração e a atenção durante a aula; promoveram interações (alunos-professor-conteúdo), participação coletiva e competitividade saudável. Com estas avaliações, foi possível verificar que vários objetivos da pesquisa foram alcançados com a aplicação do produto educacional, como provocar o interesse, incentivar a compreensão e articulação entre conteúdo e realidade do aluno, motivar interações e participação, dinamizar a aula e colaborar para a concentração. 
Sobre as respostas negativas, os apontamentos mais relevantes relacionaram-se às dificuldades de conexão (a partir de seus dispositivos móveis) com a internet wi-fi disponibilizada pela instituição de ensino; ao receio de haver dispersão da atenção, por causa de interações entre alunos ou com os smartphones, às desvantagens para aqueles que possuem celulares mais lentos e à necessidade de melhorar a interação dos alunos.

No que trata da infraestrutura escolar (conexão à internet wi-fi) e dos aparelhos (velocidade no processamento da informação), tais itens não são concebidos como pontos negativos do produto educacional em si, mas como agentes externos que podem trazer influência e/ou limitação para a eficiência da aplicação. Neste sentido, evidencia-se a necessidade de verificação prévia das condições destes agentes, de forma a favorecer a utilização destas tecnologias em sala de aula.

Quanto à apreensão pela ocorrência de dispersão dos alunos, ressalta-se que a distração costuma ser minimizada durante os jogos, dada a exigência de velocidade e de raciocínio para responder. Independente do tipo de aula ministrada, é corriqueiro ao docente lidar e encontrar soluções para situações como as citadas. A interação com os dispositivos móveis deve ser pautada por diálogo, responsabilidade e confiança mútua entre professor/aluno, sendo cada caso analisado individualmente, na busca da melhor forma de conduzir a aula, incluída a possibilidade de guardar os aparelhos durante as explicações.

Referente à interação entre alunos, docente e conteúdo, a adaptação da aula para este objetivo deve ser realizada pelo professor, que preparará e conduzirá a aula conforme as necessidades da turma.

Na última questão, foi solicitado aos alunos que avaliassem a contribuição que o produto educacional pode oferecer para a reflexão sobre as relações de trabalho durante a história e a associação com suas realidades. Esta questão, em especial, trata da relevância do produto educacional na formação dos alunos, considerando os conceitos do EMI utilizados neste trabalho. Na percepção de $76(86,4 \%)$ dos discentes estas atividades podem contribuir, para 4 $(4,5 \%)$ elas podem não colaborar e $8(9,1 \%)$ não souberam responder (Gráfico 7$)$.

Gráfico 7: "Em sua opinião, estas atividades podem contribuir para a sua reflexão sobre as diferentes formas e relações de trabalho nos períodos históricos e para a associação ao seu cotidiano?"

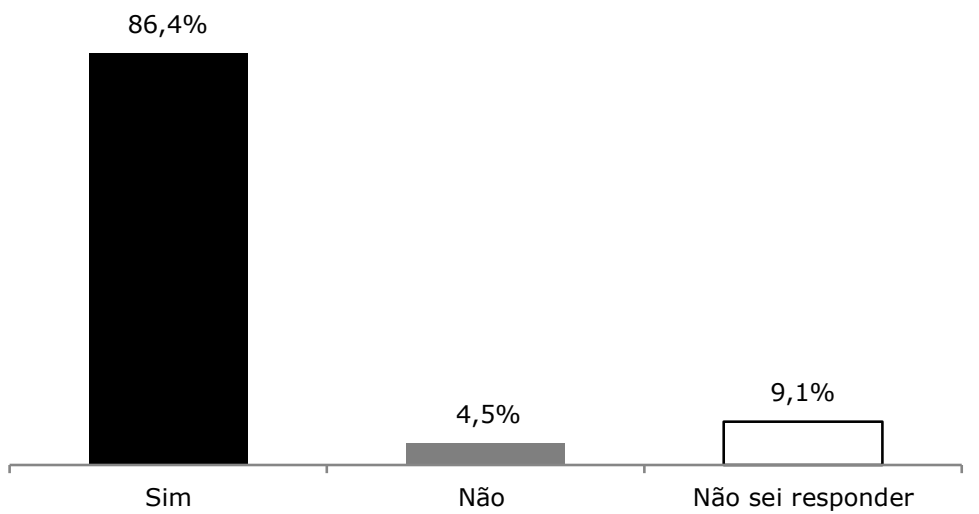


Fonte: autora.

Assim, a maioria dos alunos considerou que o recurso contribuiu para sua reflexão sobre o tema proposto, que visava provocar o pensamento crítico sobre os fatos históricos, relacionando-os ao presente, de forma a colaborar para a formação de cidadãos com consciência de seus papéis na sociedade.

\section{Considerações finais}

Este trabalho teve como objetivo a criação de um produto educacional que colaborasse para o ensino de História, considerando dificuldades como desinteresse pelos conteúdos e metodologias de ensino pouco motivadoras.

Se a proposta do Ensino Médio Integrado é proporcionar uma formação omnilateral, na qual o indivíduo se apropria de diferentes conhecimentos e a partir deles constrói sua história, torna-se imprescindível aprender e refletir sobre os fatos históricos que embasam o presente. Por isso, a necessidade de se propor novas formas para se ensinar História encaminhou a pesquisa para o envolvimento de tecnologias no desenvolvimento do produto educacional, considerando a familiaridade dos jovens com essas inovações. A escolha do tema "Relações de trabalho na História do Brasil" pautou-se na abordagem de assuntos importantes para o futuro trabalhador, podendo ser associados a sua realidade e provocar a reflexão.

Desta forma, foi idealizado um recurso didático envolvendo jogos digitais e dispositivos móveis. A sua aplicação foi realizada com alunos do $4^{\circ}$ ano do Ensino Médio Integrado informática, tendo sido avaliado positivamente em aspectos como: tornar a aula mais interessante e dinâmica, motivar a participação, facilitar o aprendizado e a associação dos conteúdos ao cotidiano, estimular a concentração e a atenção durante a aula, promover a participação coletiva e interações diversas.

Alguns possíveis obstáculos tecnológicos foram apontados, como dificuldades de conexão com a internet wi-fi e problemas com celulares lentos. Desta forma, orienta-se a prévia verificação de infraestrutura e suporte tecnológico na escola, considerando-se a quantidade de

alunos participantes, a disponibilidade, a estabilidade, a velocidade e o alcance do wi-fi. Quanto à lentidão dos dispositivos móveis, sugere-se a adaptação do jogo (um celular por dupla ou equipe).

A partir dos resultados, foi possível verificar que o produto educacional, na percepção dos participantes, pode colaborar para o ensino-aprendizagem na disciplina de História no Ensino Médio Integrado, uma vez que despertou o interesse e os motivou à participação ativa das aulas, promovendo interação com o conteúdo a partir de tecnologias e jogos no aprendizado. Além disso, destacar questões históricas que influenciam a vida do cidadão (políticas, sociais, educacionais e trabalhistas) foi considerado um estímulo à reflexão e articulação à situação contemporânea, concluindo-se que o material possui aspectos contributivos à proposta de 
formação omnilateral no Ensino Médio Integrado e para a busca da superação da dualidade educacional.

Além disso, entendeu-se que os quizzes podem proporcionar maior motivação e engajamento nas aulas por incentivar os alunos a observarem a influência dos acontecimentos em suas vidas e identificarem-se como parte do processo de construção do presente da sociedade. A associação de jogos digitais ao conteúdo também pode estimular a participação nas aulas, uma vez que esse tipo de TIC não costuma ser utilizado e os quizzes gamificados na plataforma Game-Based Learning contêm semelhanças com os jogos comerciais, como layout, trilha sonora, cores, formas, ranking e tempo cronometrado.

Considerando a avaliação positiva, evidencia-se a importância do desenvolvimento de produtos educacionais que auxiliem o docente do Ensino Médio Integrado na promoção da educação integradora e que contribuam para a proposta de educação libertadora, estimulando os sujeitos a participarem ativamente da construção da sociedade que desejam.

\section{Referências}

AMORIM, M. C. M. S. et al. Aprendizagem e Jogos: diálogo com alunos do ensino médio-técnico. In: Educação \& Realidade, v.41, n.1, p. 91-115, jan./mar. 2016. Disponível em: <http://seer.ufrgs.br/index.php/educacaoerealidade/article/view/56109>. Acesso em: 20 mai. 2018.

CAIMI, F. E. Por que os alunos (não) aprendem História? Reflexões sobre ensino, aprendizagem e formação de professores de História. Tempo, [s.I.], v. 11, n. 21, p.17-32, jun. 2006. FapUNIFESP (SciELO). Disponível em: <www.scielo.br/pdf/tem/v11n21/v11n21a03>. Acesso em: 23 abr 2018.

CAMPELLO, A. M. Dualidade Educacional. In: PEREIRA, I. B.; LIMA, J. C. F. (Org.). Dicionário da Educação Profissional em Saúde. 2. ed. Rio de Janeiro: Fundação Oswaldo Cruz - Escola Politécnica de Saúde Joaquim Venâncio, 2009 (online). Disponível em: <http://www.sites.epsjv.fiocruz.br/dicionario/verbetes/duaedu.html>. Acesso em: 26 dez. 2017.

CHIOFI, L. C.; OLIVEIRA, M. R. F. O uso das tecnologias educacionais como ferramenta didática no processo de ensino e aprendizagem. III Jornada de didática: desafios para a docência e II seminário de pesquisa do CEMAD. p. 329-337, $2014 . \quad$ Disponível em: <http://www.uel.br/eventos/jornadadidatica/pages/anais-da-iii-jornada-de-didatica-desafios-para-adocencia-e-ii-seminario-de-pesquisa-do-cemad.php>. Acesso em: 13 jan. 2018.

CIAVATTA, M. A formação integrada: a escola e o trabalho como lugares de memória e de identidade. Trabalho Necessário, v.3, n.3, $2005 . \quad$ Disponível em: <http://www.uff.br/trabalhonecessario/images/TN_03/TN3_CIAVATTA.pdf>. Acesso em: 16 jan. 2017.

ESQUIVEL, H. C. R. Gamificação no ensino da matemática: uma experiência no ensino fundamental. 2017. 64 f. Dissertação (Mestrado Profissional em Matemática em Rede Nacional - PROFMAT). Instituto de Ciências Exatas, Universidade Federal Rural do Rio de Janeiro. Seropédica, 2017. Disponível em: <https://sca.profmat-sbm.org.br/sca_v2/get_tcc3.php?id=150510921>. Acesso em: 18 mai. 2018.

FIGUEIREDO, M., PAZ, T., JUNQUEIRA, E. Gamificação e educação: um estado da arte das pesquisas realizadas no Brasil. Anais dos Workshops do IV Congresso Brasileiro de Informática na Educação, 2015. Disponível em: <www.br-ie.org/pub/index.php/wcbie/article/view/6248>. Acesso: 27 out. 2017.

GIL, A. C. Como elaborar projetos de pesquisa. 5 ed. São Paulo: Atlas, 2010. 
KUENZER, A. Z.; LIMA, H. R. As relações entre o mundo do trabalho e a escola: a alternância como possibilidade de integração. Educação UFSM, v. 38, n. 3, p. 523-536, set./dez. 2013. Disponível em: <https://periodicos.ufsm.br/index.php/reveducacao/article/view/8989>. Acesso em: 10 jan. 2018.

LAVILLE, C.; DIONNE, J. A construção do saber: manual da pesquisa em ciências humanas. Porto Alegre: Artmed; Belo Horizonte: Editora UFMG, 1999.

LEITÃO, R. M. V. Aprendizagem baseada em jogos: realidade aumentada no ensino de sólidos geométricos. 2013. 77 f. Dissertação (Mestrado em Expressão Gráfica e Audiovisual). Programa de Pós-Graduação em Expressão Gráfica e Audiovisual, Universidade Aberta. Lisboa, 2013. Disponível em: <https://repositorioaberto.uab.pt/handle/10400.2/3015 >. Acesso em: 19 mai. 2018.

LEONARDOS, A. N.; GOMES, C. A.; WALKER, R. K. Estudo de caso aplicado às inovações educacionais: uma metodologia (edição reformulada). Série Documental. Inovações, n. 4, jul. 2014. Brasília: INEP/MEC, 1994. Disponível em: < http://www.dominiopublico.gov.br/download/texto/me001872.pdf >. Acesso em: 01 jun. 2018.

LIMA, R. G. Depois do e- e do b-, o m- e o u-(learning): uma breve incursão pelos paradigmas emergentes da educação à distância. História: Revista da FLUP. IV Série, vol. 6, p. 141-157, 2016. Universidade do Porto. Disponível em: <http://ojs.letras.up.pt/index.php/historia/article/view/1723>. Acesso em: 19 mai. 2018.

MORAES, R. A. Educação, trabalho e novas tecnologias: o debate teórico. In: Pereira, M. F. R.; Moraes, R. A; Teruya, T. K. (Orgs). Educação a distância (EaD): reflexões críticas e práticas. 1 ed. Uberlândia: Editora Navegando, v.1, p. 55-66, $2017 . \quad$ Disponível em: <https://www.ead.unb.br/arquivos/livros/ead_reflexoes_critica_praticas.pdf>. Acesso em: 02 jan. 2018.

MOURA, D. H. Educação básica e educação profissional e tecnológica: dualidade histórica e perspectiva de integração. Holos, Natal, v.2, p.1-27, 2007. Disponível em:< http://www2.ifrn.edu.br/ojs/index.php/HOLOS/article/viewFile/11/110>. Acesso em: 10 dez. 2017.

OLIVEIRA, M. R. et al. Aprendizagem baseada em jogos digitais: Uso de simulador de estratégia como instrumento pedagógico na educação a distância. In: Educação no Século XXI. 1 ed. v. 5. Belo Horizonte: Poisson, 2018. Cap. 20, p. 146-151. E-book. Disponível em: <http://poisson.com.br/bs/produto/educacaono-seculo-xxi-volume-5/>. Acesso em: 11 jun. 2018.

PEREIRA, P. C.; PEREIRA, R. S.; ALVES, J. C. Ambientes virtuais e mídias de comunicação, abordando a explosão das mídias na sociedade da informação e seu impacto na aprendizagem - o uso do WhatsApp como plataforma de m-learning. Revista Mosaico, [s.I.], v. 6, n. 1, p. 29-41, 2015. Disponível em: <http://editorauss.uss.br/index.php/RM/article/view/130>. Acesso em: 05 jan. 2018.

PRENSKY, Marc. Aprendizagem baseada em jogos digitais. São Paulo: Editora Senac São Paulo, 2012.

PRODANOV, C. C.; FREITAS, E. C. Metodologia do trabalho científico: métodos e técnicas da pesquisa e do trabalho acadêmico. 2. ed. Novo Hamburgo: Feevale, 2013. E-book. Disponível em: <http://www.feevale.br/Comum/midias/8807f05a-14d0-4d5b-b1ad-1538f3aef538/Ebook\%20Metodologia\%20do\%20Trabalho\%20Cientifico.pdf>. Acesso em: 20 jan. 2018.

RAMOS, M. N. História e política da educação profissional. 1 ed. Curitiba: Instituto Federal do Paraná, 2014. (Coleção formação pedagógica; v. 5). Disponível em: <http://curitiba.ifpr.edu.br/wpcontent/uploads/2016/05/Hist\%C3\%B3ria-e-pol\%C3\%ADtica-da-educa\%C3\%A7\%C3\%A3oprofissional.pdf>. Acesso em: 24 abr. 2018.

SENA, S. et al. Aprendizagem baseada em jogos digitais: a contribuição dos jogos epistêmicos na geração de novos conhecimentos. RENOTE, [s.I.], v. 14, n. 1, p. 1-11, 2016. Universidade Federal do Rio Grande do Sul. http://dx.doi.org/10.22456/1679-1916.67323. Disponível em: <http://seer.ufrgs.br/index.php/renote/article/view/67323>. Acesso em: 21 mai. 2018. 
SEVERINO, A. J. Metodologia do Trabalho Científico. 23 ed. ver. atual. São Paulo: Cortez, 2007. 304 p.

SEVERO SOBRINHO, A. A História não é "decoreba": Os desafios do Ensino de História no Ensino Médio na Escola Estadual Adriano Feitosa - Tavares - PB. 2014. 62 f. Monografia (Especialização) - Curso de Fundamentos da Educação: Práticas Pedagógicas Interdisciplinares, Universidade Estadual da Paraíba, Princesa Isabel, 2014. Disponível em: <http://dspace.bc.uepb.edu.br/jspui/handle/123456789/6652>. Acesso em: $10 \mathrm{dez} .2017$.

SILVA, C. G.; FIGUEIREDO, V. F. Os desafios da educação contemporânea: o ensino de História e o emprego das novas tecnologias. Revista Opsis, [s.I.], v. 13, n. 1, p.99-119, 27 set. 2013. Universidade Federal de Goias. http://dx.doi.org/10.5216/o.v13i1.20483. Disponível em: <https://www.revistas.ufg.br/Opsis/article/view/20483>. Acesso em: 24 abr. 2018.

SILVA JÚNIOR, A. F.; SILVA, L. M. R.; SANTOS, R. M. Dossiê: Linguagens, tecnologias da informação e ensino de História. Revista Opsis, [s.I.], v. 13, n. 1, p.9-14, 27 set. 2013. Universidade Federal de Goiás. http://dx.doi.org/10.5216/o.v13i1.26611. Disponível em: <https://revistas.ufg.br/Opsis/article/download/26611/15166>. Acesso em: 10 abr. 2018.

SOUSA. L. L.; PEREIRA, A. L. Jogos digitais no ensino de História: aliando os games às práticas de ensino tradicionais. Anais V Encontro de Iniciação à Docência da UEPB. Universidade do Estado da Paraíba. [s.I.]: Editora Realize, 2015.2 Disponível em: <https://editorarealize.com.br/revistas/eniduepb/trabalhos/TRABALHO_EV043_MD1_SA6_ID45_29062015 085818.pdf>. Acesso em: 21 mai 2018.

SOUZA, K. R.; KERBAUY, M. T. M. Abordagem quanti-qualitativa: superação da dicotomia quantitativaqualitativa na pesquisa em educação. Educação e Filosofia, Uberlândia, v. 31, n. 61, p. 21-44, 2017. Disponível em: <http://www.seer.ufu.br/index.php/EducacaoFilosofia/article/view/29099>. Acesso em: 25 jan. 2018.

TAVARES, M. G. Evolução da Rede Federal de Educação Profissional e Tecnológica: as etapas históricas da educação profissional no Brasil. In: ANPED SUL - SEMINÁRIO DE PESQUISA EM EDUCAÇÃO DA REGIÃO SUL, 9, 2012, Caxias do Sul. Apresentação. Caxias do Sul: Conferências USC, 2012, p. 1-21. Disponível em: $\quad$ http://www.ucs.br/etc/conferencias/index.php/anpedsul/9anpedsul/paper/viewFile/177/103>. Acesso em: 26 dez. 2017

UNESCO. Policy Guidelines for Mobile Learning. Disponível em: <http://unesdoc.unesco.org/images/0022/002277/227770por.pdf>. Acesso em: 27 out. 2017.

VIEIRA, A. M. D. P.; SOUZA JUNIOR, A. A educação profissional no Brasil. Revista Interaç̧ões, [s.I.], v. 12. n. 40, p 152-169, 2016. Disponível em: <http://revistas.rcaap.pt/interaccoes/article/view/10691/7655>. Acesso em 26 dez. 2017.

Recebido em novembro de 2019.

Aprovado para publicação em junho de 2020

\section{Priscila Cabreira de Freitas}

Programa de Mestrado Profissional em Educação Profissional e Tecnológica em Rede Nacional - Instituto Federal de Educação, Ciência e Tecnologia de São Paulo - IFSP, Brasil, pricabreira1@gmail.com

\section{Danilo Fischer}

Programa de Mestrado Profissional em Educação Profissional e Tecnológica em Rede Nacional - Instituto Federal de Educação, Ciência e Tecnologia de São Paulo - IFSP, Brasil, danilofischer4@gmail.com

\section{Nemésio Freitas Duarte Filho}

Programa de Mestrado Profissional em Educação Profissional e Tecnológica em Rede Nacional - Docente em Instituto Federal de Educação, Ciência e Tecnologia de São Paulo - IFSP, Brasil, nemesiofreitas@gmail.com 